\title{
Parametric Analysis of Automotive Grade Buck Converters
}

\author{
Vajra R Singh $^{1}$,Sindhu Rajendran \\ Electronics and Communication \\ Dept. ${ }^{1,2}$,R.V College of \\ Engineering, Bangalore, India \\ vajrarsingh.ec17@rvce.edu.in ${ }^{1}$,sindhur@rvce.edu.in²
}

\begin{abstract}
The current power system design in electric automobiles has become increasingly complicated due to innumerable electronics which are required to be integrated for the effective functioning of the system. A DC/DC buck converter is primarily used in order to control and regulate the working of peripheral systems in an automotive, the voltage from the battery is stepped down in order to power systems like the USB ports and the dashboard interfaces. There are multiple regulators available but in order to assess the feasibility of the available IC's to interface, the design characteristics and specifications requires stepping down the input voltage from a higher voltage to produce a requirement specific lower voltage and constant output current in amperes. A comprehensive parametric analysis of LM23625 and LM23630 is performed by simulating buck regulators operating at respective switching frequencies.
\end{abstract}

\section{Keywords: Automotive, Buck Converters, DC/DC Converter, Integrated Circuit, Regulators, WEBENCH}

\section{INTRODUCTION}

A buck converter is used to enable step down DC-DC conversion of input voltage to a required lower output voltage in power supplies. The primary requirement of a buck converter is efficient conversion of power which results in stable output and hence reduces the electromagnetic interference with the other electrical circuits of the automobile, it should minimum footprint yielding it to be small and compact an thereby the power dissipation by heat is reduced to a minimum, another vital factor to be considered is the operating temperature range, since an automobile is subjected to erratic temperature situations, the converter must be able to sustain the same. Buck converter is primarily used in infotainment systems, telematics and chagrin modules.

The converter is designed to supply power to the peripheral systems of an automotive vehicle where the input is given through the battery management system ranging from $8 \mathrm{~V}-32 \mathrm{~V}$ and the output is designed to be a constant voltage and maximum current measured in amperes.

The specification of the converter is designed based on application requirements and adhering to the standard regulations. The design of the DC-DC Converter is simulated by using suitable design inputs on two different buck regulator topology IC's LM23625 and LM23630 and their performance parameters are measured and compared in order to determine the best fit.

\section{Methodology}

The primary step is to design the high level specifications of the power supply and perform the simulation and comparison based on the same.The design of the power converter is carried out by identifying the requirements of the automotive telematics control unit and designing the high level specifications adhering to it. Based on the specifications, the topology is selected and the converter is designed using LM23625 and LM23630 following which a suitable switching frequency is determined The simulation of the design basedon tradeoff is carried out by a power 
designer tool,WEBENCH and the results are monitored and parametric comparison is performed inorder to conclude the best suited design for the requirement.

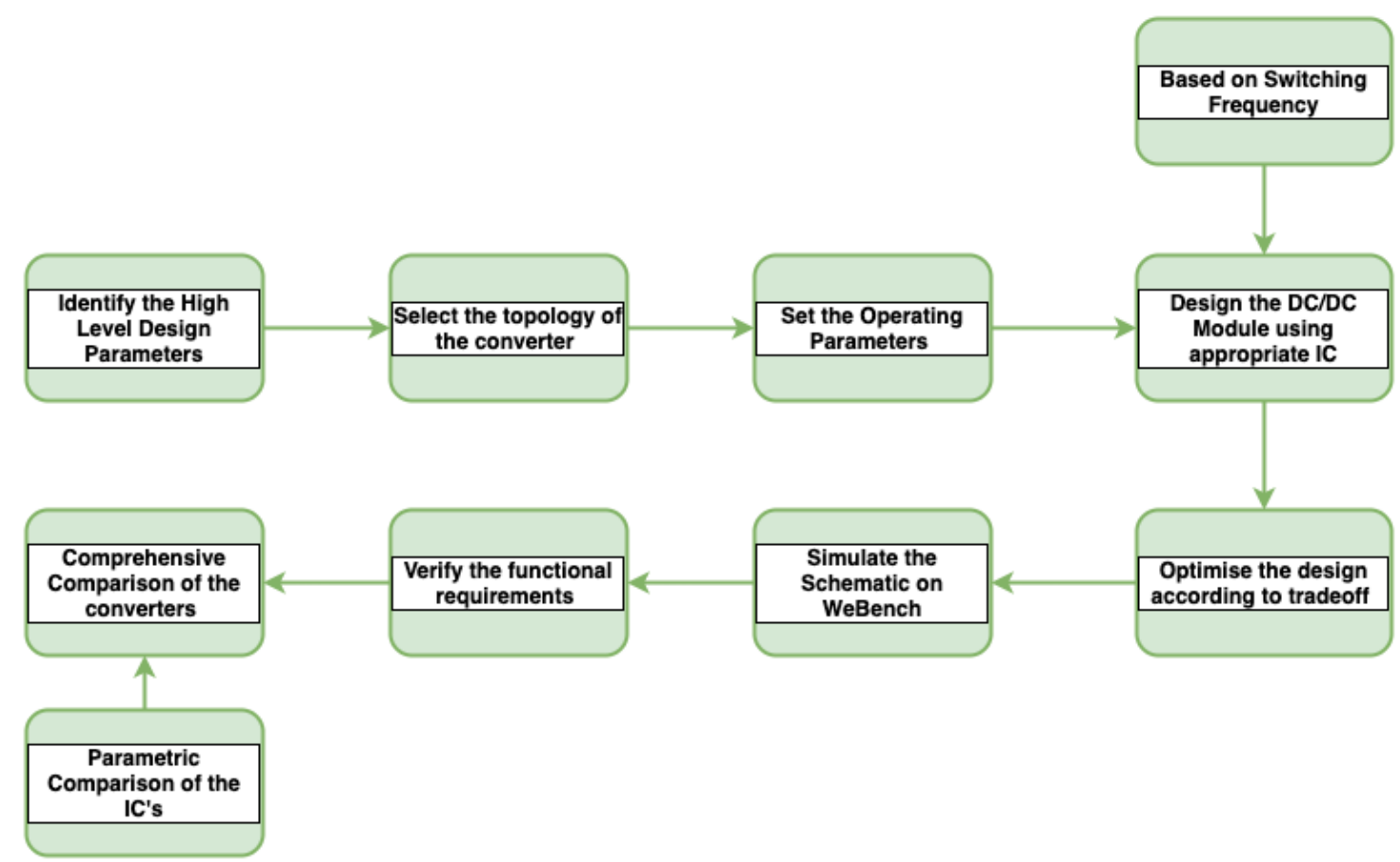

Figure 1. Design Methodology of the Buck Converter

\subsection{IC Specifications}

The two buck converter regulator integrated circuits being used for simulation and comparison are Texas Instruments LM23625 and LM23630, the specifications are tabulated as follows:

Table 1. Specifications of LM23625 and LM23630

\begin{tabular}{|c|c|c|}
\hline Parameters & LM23625 & LM23630 \\
\hline Input Voltage Range & $4 \mathrm{~V}-36 \mathrm{~V}$ & $4 \mathrm{~V}-36 \mathrm{~V}$ \\
\hline Output DC Current & $2.5 \mathrm{~A}$ & $3 \mathrm{~A}$ \\
\hline Switching Frequency & $\begin{array}{c}200 \mathrm{kHz}- \\
2.2 \mathrm{MHz}\end{array}$ & $\begin{array}{c}200 \mathrm{kHz}- \\
2.2 \mathrm{MHz}\end{array}$ \\
\hline $\begin{array}{c}\text { Normal Operating } \\
\text { Frequency }\end{array}$ & $2100 \mathrm{kHz}$ & $400 \mathrm{kHz}$ \\
\hline Mode of Operation & $\begin{array}{c}\text { Continuous } \\
\text { Current } \\
\text { Mode } \\
\text { (CCM) }\end{array}$ & $\begin{array}{c}\text { Continuous } \\
\text { Current Mode } \\
\text { (CCM) }\end{array}$ \\
\hline Control Unit & $\begin{array}{c}\text { Forced } \\
\text { PWM }\end{array}$ & $\begin{array}{c}\text { Forced PWM } \\
\text { Features }\end{array}$ \\
$\begin{array}{c}\text { Under } \\
\text { Voltage } \\
\text { Lockout } \\
\text { (UVLO), } \\
\text { Precision }\end{array}$ & $\begin{array}{c}\text { Under Voltage } \\
\text { Lockout } \\
\text { (UVLO), } \\
\text { Precision Enable }\end{array}$ \\
\hline \multicolumn{2}{|c|}{} \\
\hline
\end{tabular}




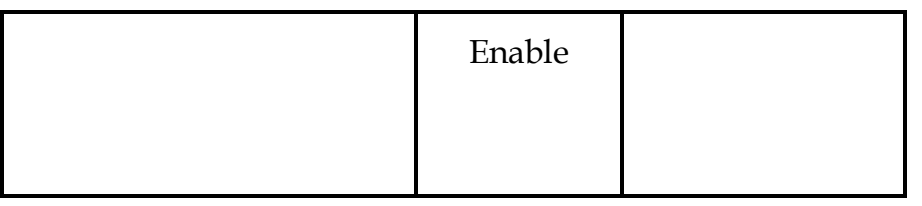

\section{Implementation}

The LM23625 circuit is designed based on the required design inputs, thepassive.components are designed based on the input and output voltage requirement. The switching frequency is $1.38 \mathrm{MHz}$ and all the components are designed accordingly.

LM23625 provides an additional feature to design an EMI filter based on the Line Impedance Stabilization Network(LISN) requirement in order to effectively reduce the output noise ripple and satisfy the criteria to adhere to CISPR 25 Class 3 standards.

Whereas the LM23630 circuit is designed based on the required design inputs, the passive components are designed based on the input and output voltage requirement. The switching frequency is $400 \mathrm{kHz}$ and all the components are designed accordingly. The IC is internally compensated by a compact design and there is no separate provision to design an EMI Filter.

The electrical simulation of the circuits is carried out using the WEBENCH tool and the flowchart for the implementation is given below:

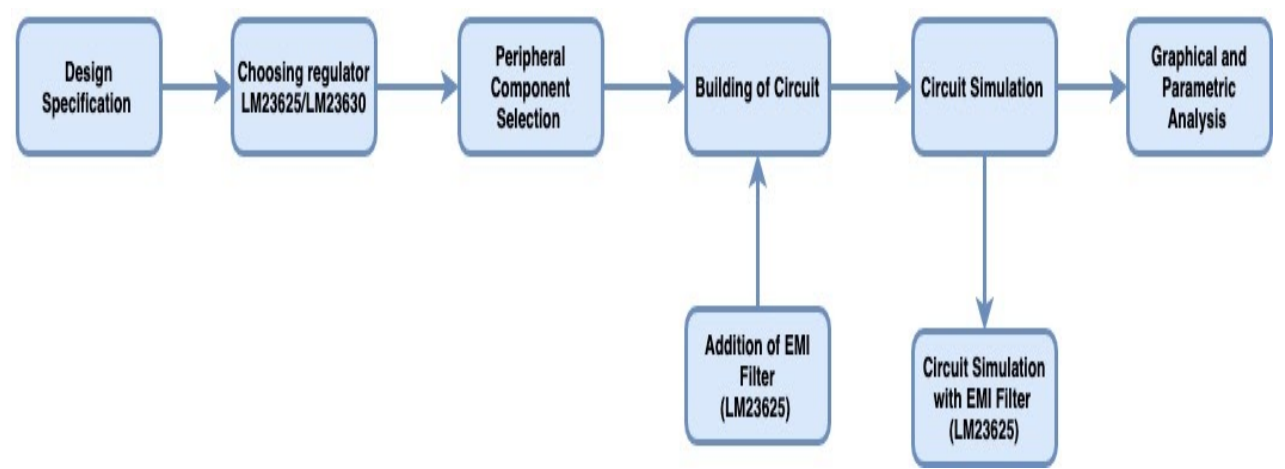

Figure 2. Circuit Design using WEBENCH

\section{Results and Comparisons}

The graphical representation of electrical simulation of vital factors as described in Fig 2 and the parameters for comparison are elucidated in this section.

\subsection{Parameters}

1. Switching Frequency : directly affects the footprint, as the frequency increases, the size of the passive components decreases which in turn directly affects the footprint.

2. Efficiency: is the main objective of using DC/DC converter as they deliver high efficiency

3. Footprint : of the circuit is very vital as the buck converter circuit only forms a small aspect of a very large automobile system, hence the criteria is for it to be compact and lightweight. 
4. Duty Cycle : efficiency are interdependent as the duty cycle determines the high frequency pulses which will be passed on to the PWM control unit based on which efficiency of the system can be estimated

5. Ripple : of the output voltage disrupts the working of the system due to the inability to provide a constant output.

6. Noise Filter : curbs the external noise affecting the circuit and also the radio frequency noise which may be generated by the input power sources from coupling with the circuit

7. Variable Frequency: is required in order to perform versatile operation of the circuit under varying load conditions.

8. Device Temperature : plays a role when the design is imprinted on a PCB

\subsection{Simulation Results}

TheLM23635 and LM23630 are simulated for 3 vital parameters, duty cycle, efficiency and output voltage ripple.

\subsubsection{LM23625}

\section{EFFICIENCY}

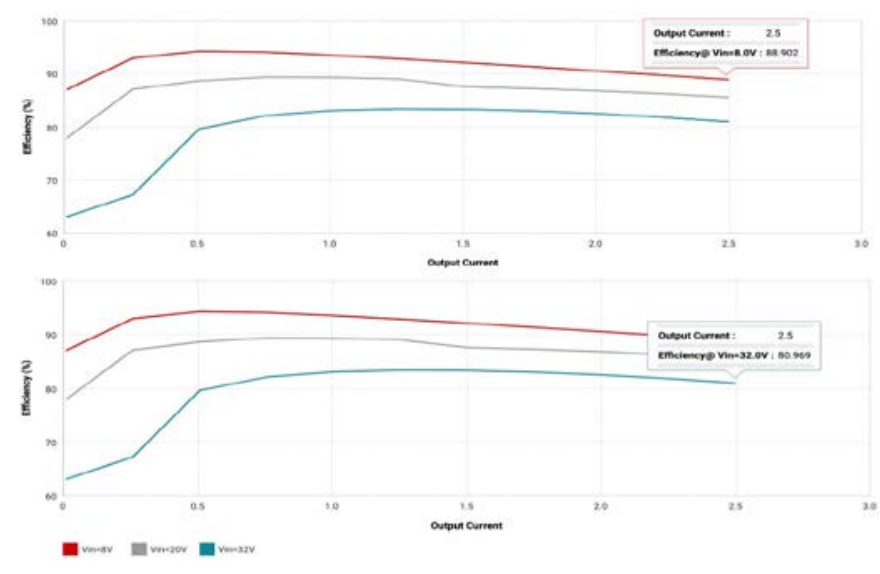

Figure 3.LM23625 Efficiency 


\section{OUTPUT RIPPLE VOLTAGE}

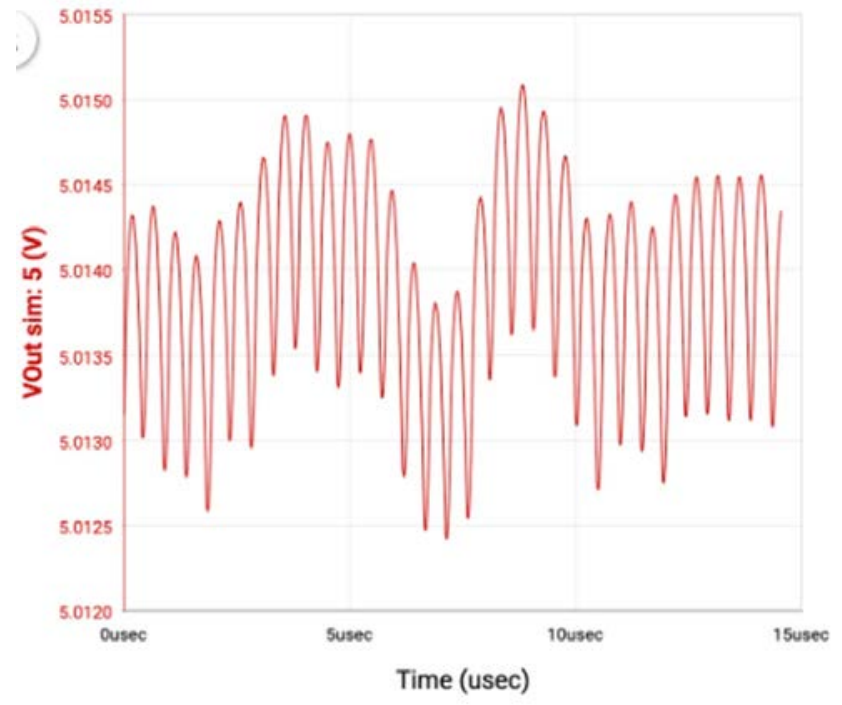

Performance Summary

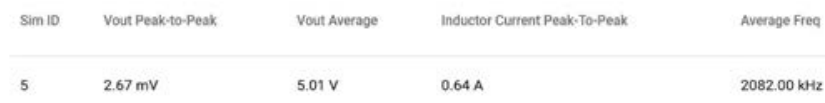

Figure 4. LM23625 Output Ripple Voltage

\section{DUTY CYCLE}
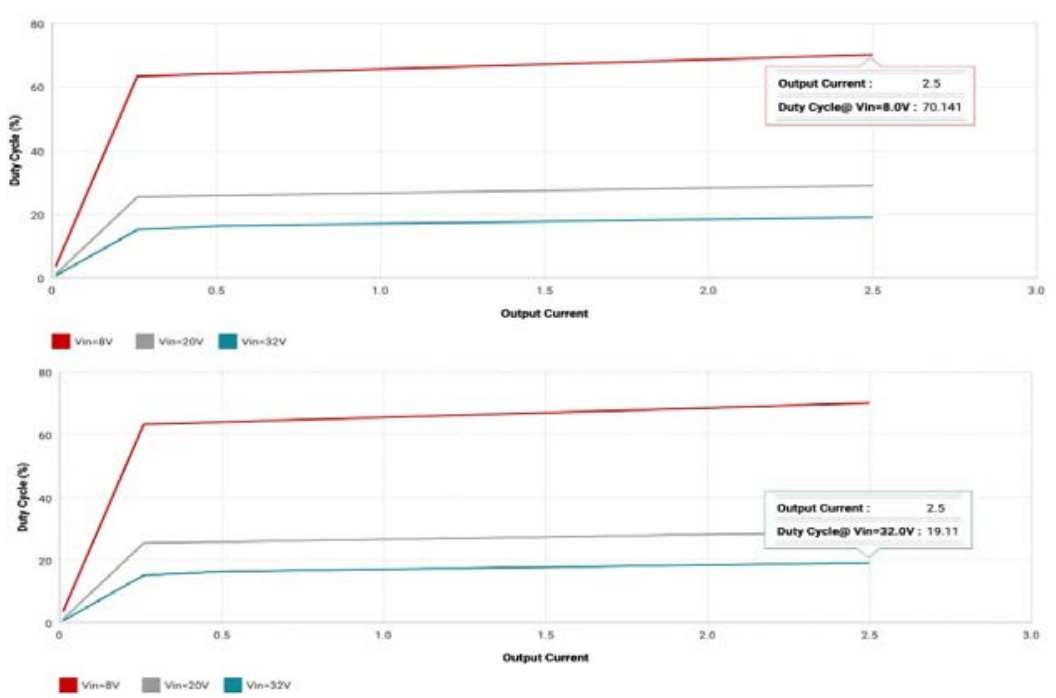

Figure 5.LM23625 Duty Cycle

\subsubsection{LM23630:}

\section{EFFICIENCY}

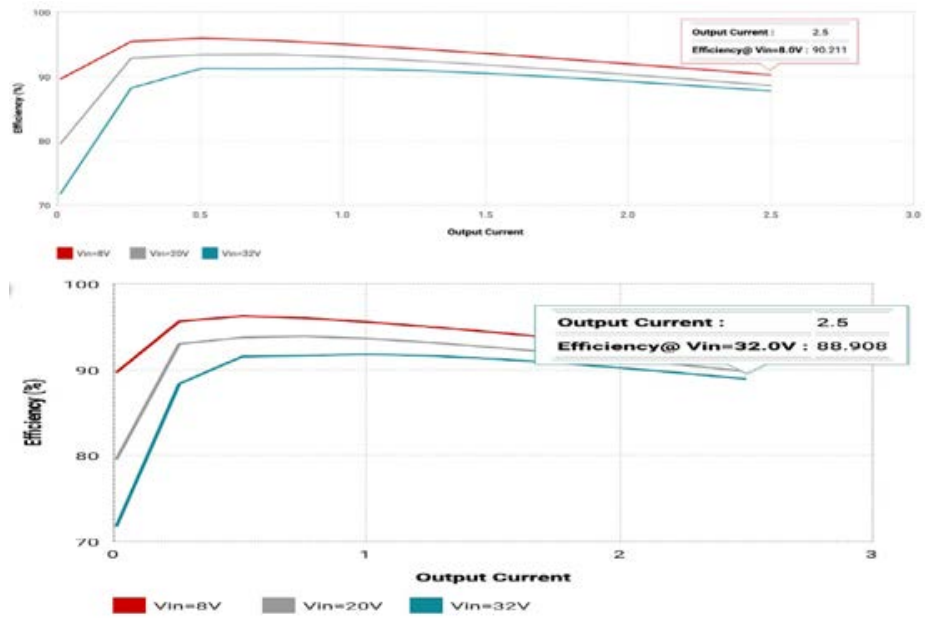

Figure 6. LM23630 Efficiency 


\section{OUTPUT VOLTAGE RIPPLE}

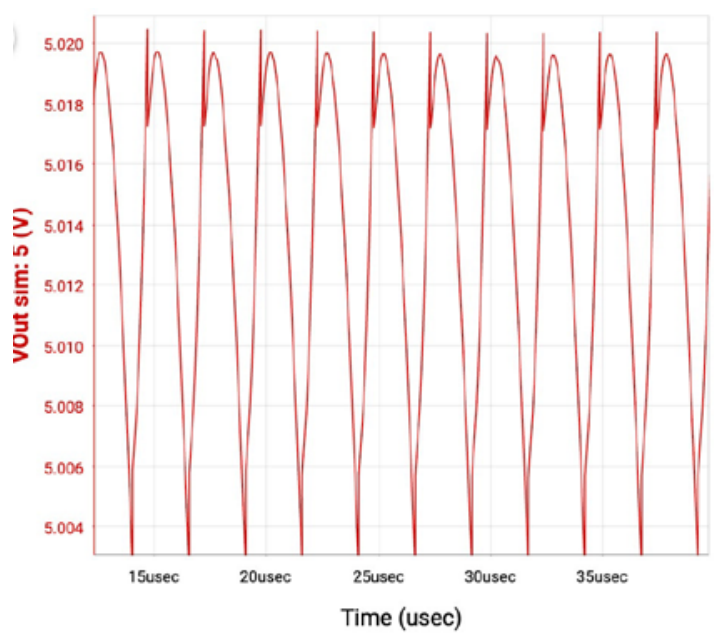

Performance Summary

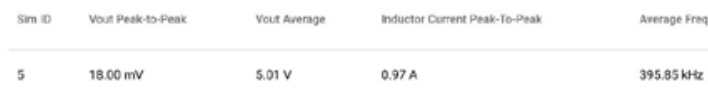

Figure 7. LM23630 Output Voltage Ripple

\section{DUTY CYCLE}
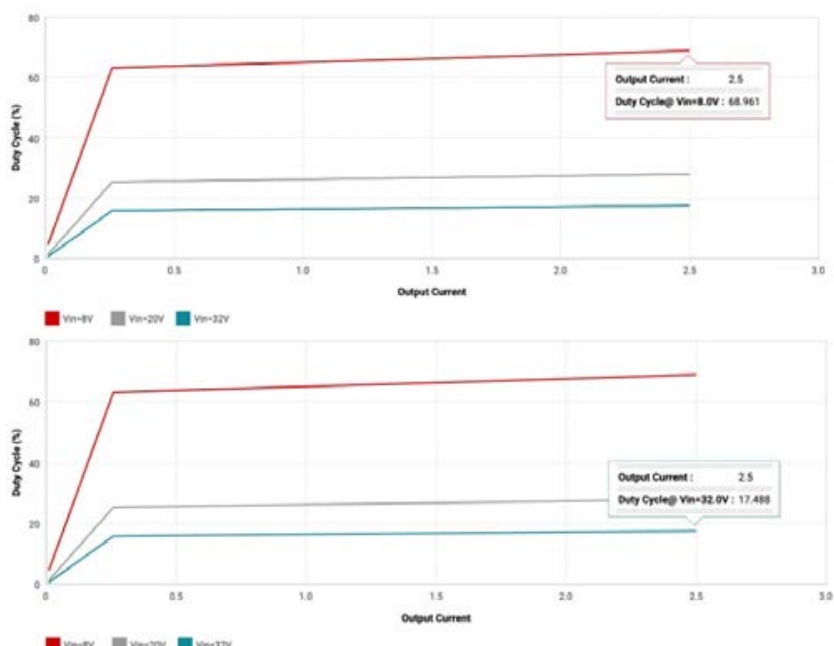

Figure 8. LM23630 Duty Cycle

\subsection{Parametric Analysis}

The parameters of simulation are compared and tabulated in the table below:

Table 2 : Parametric Comparison

\begin{tabular}{|c|c|c|}
\hline Parameters & LM23625 & LM23630 \\
\hline Switching Frequency & $1.38 \mathrm{MHz}$ & $400 \mathrm{kHz}$ \\
\hline Efficiency at 20V & $83.7 \%$ & $87.7 \%$ \\
\hline Footprint & $232 \mathrm{~mm}^{2}$ & $448 \mathrm{~mm}^{2}$ \\
\hline Duty cycle at 20V & $18.5 \%$ & $17.49 \%$ \\
\hline
\end{tabular}




\begin{tabular}{|c|c|c|}
\hline Output Voltage Ripple & $2.67 \mathrm{mv}$ & $18 \mathrm{mv}$ \\
\hline Noise Filter & $\begin{array}{c}\text { EMI filter can be } \\
\text { added }\end{array}$ & $\begin{array}{c}\text { Internal } \\
\text { Compensation }\end{array}$ \\
\hline Variable Frequency & $\begin{array}{c}\text { Synchronized to } \\
\text { External Clock }\end{array}$ & $\begin{array}{c}\text { RT Pin } \\
\text { available }\end{array}$ \\
\hline Soft Start Time & $200 \mathrm{~ms}$ & $200 \mathrm{~ms}$ \\
\hline Device Temperature & $111.64{ }^{\circ} \mathrm{C}$ & $97.84{ }^{\circ} \mathrm{C}$ \\
\hline
\end{tabular}

\section{Conclusion}

It can be inferred from the analysis of the design that ideally the switching frequency of the converter is the most vital parameter considered as it directly affects the footprint of the entire design and consequently the LM23625 has a footprint of $232 \mathrm{~mm}$ per square operating at 1.38MHZ in comparison to the LM23630 which has a footprint of $448 \mathrm{~mm}$ per square operating at 400khz. Although the footprint of LM23635 serves a better purpose, the efficiency of the LM23630 is better by almost $4 \%$. This narrows it down to the noise compensation factor, it can be noticed that the ripple in the output of the LM23630 is 900\% more than that of LM23625 and this is due to the lack of an EMI filter and damping circuit. It can be concluded that for an automotive application, the LM2625 will be better suited since noise interference plays a major role in an automotive system.

\section{REFERENCES}

[1] G. -. Su and F. Z. Peng, "A low cost, triple-voltage bus DC-DC converter for automotive applications," Twentieth Annual IEEE Applied Power Electronics Conference and Exposition, 2005. APEC 2005., Austin, TX, USA, 2005, pp. 1015-1021 Vol. 2

[2] S. Tenner, S. Gimther and W. Hofmann, "Loss minimization of electric drive systems using a DC/DC converter and an optimized battery voltage in automotive applications," 2011 IEEE Vehicle Power and Propulsion Conference, Chicago, IL, USA, 2011, pp. 1-7

[3] A. Salimath et al., "An 86\% Efficiency, Wide-Vin SIMO DC-DC Converter Embedded in a CarRadio IC," in IEEE Transactions on Circuits and Systems I: Regular Papers, vol. 66, no. 9, pp. 3598-3609, Sept. 2019

[4] Isurin, Alexander \& Cook, Alexander. (2016) "Step-up DC-DC converter for automotive application". 1-9. 10.1109/EPE.2016.7695284

[5] Fan Zhang, F. Z. Peng and Zhaoming Qian, "Study of the multilevel converters in DC-DC applications," 2004 IEEE 35th Annual Power Electronics Specialists Conference (IEEE Cat. No.04CH37551), Aachen, Germany, 2004, pp. 1702-1706 Vol.2

[6] T. C. Neugebauer and D. J. Perreault, "Computer-aided optimization of DC/DC converters for automotive applications," in IEEE Transactions on Power Electronics, vol. 18, no. 3, pp. 775-783, May 2003 